\title{
Genetic Variation in Puccinia graminis Collected from Oats, Rye, and Barberry
}

\author{
Anna Berlin, Annika Djurle, Berit Samils, and Jonathan Yuen
}

Department of Forest Mycology and Plant Pathology, Swedish University of Agricultural Sciences, Box 7026, SE-750 07 Uppsala, Sweden. Accepted for publication 18 June 2012.

\begin{abstract}
Berlin, A., Djurle, A., Samils, B., and Yuen, J. 2012. Genetic variation in Puccinia graminis collected from oats, rye, and barberry. Phytopathology 102:1006-1012.

Puccinia graminis, the causal agent of stem rust, was collected from its alternate host barberry (Berberis spp.) and two different uredinial hosts, oats (Avena sativa) and rye (Secale cereale). The samples were analyzed using 11 polymorphic simple sequence repeat (SSR) markers. There were

large differences between fungal populations on oats ( $P$ graminis $\mathrm{f}$. $\mathrm{sp}$. avenae) and rye ( $P$. graminis $\mathrm{f}$. sp. secalis), and the genetic variation within the different formae speciales was also high. It was possible to distinguish between the two formae speciales on barberry. Additional genotypic groups not present in the field samples from oats and rye were also identified on barberry. Our results confirm the importance of barberry in maintaining the populations of $P$. graminis in Sweden and the importance of the sexual stage for the survival of the pathogen.
\end{abstract}

Stem rust, caused by Puccinia graminis (Pers.), is a serious disease of cereal crops in grain producing areas of the world. Puccinia graminis is a biotrophic fungus and its urediniospores have been reported to infect 365 different grass species, including economically important crops such as wheat, rye and oats (24). Being a heteroecious rust, it needs an alternate host to complete its sexual life cycle. Gäumann (13) reported over 70 Berberis species and some species of Mahonia to be alternate hosts for $P$. graminis. The most frequently found alternate host in Sweden is common barberry (Berberis vulgaris), and the incidence of barberry has increased during the last decades $(5,9,11,14$, $22,32,34)$ due to the repeal of the Swedish law of barberry eradication, which was in force between 1918 and 1994. Other Berberis species and hybrids are also present in this country. The presence of both barberry and the uredinial hosts is needed by the pathogen to complete its life cycle, and allows it to permanently occupy a certain geographic area. Barberry also provides a source of initial inoculum for infection on the seasonal, uredinial, host (30). The sexual reproduction enables the fungus to recombine its genes and resulting in new virulence combinations (25), some of which may have serious consequences for cereal crop production (17).

Formae speciales and subspecies denomination. Eriksson and Henning (10) subdivided P. graminis into specialized forms or formae speciales (f. sp.), which reflect the fungus' parasitic adaptation to certain genera of grass hosts. The subdivisions have been supported by crossing studies and comparisons of DNA sequences (24). Johnson (20) found that the $P$. graminis f. sp. tritici and $P$. graminis f. sp. secalis infecting wheat and rye respectively, were closely related whereas the $P$. graminis f. sp. avenae, infecting oats, clearly differed from the other two. Urban (35) divided $P$. graminis into different subspecies and varieties based primarily on morphology, of which $P$. graminis subsp.

*Corresponding author: A. Berlin; E-mail address: anna.berlin@slu.se

* The $\boldsymbol{e}$-Xtra logo stands for "electronic extra" and indicates that the online version contains one supplementary table.

http://dx.doi.org/10.1094/PHYTO-03-12-0041-R

(C) 2012 The American Phytopathological Society graminis var. graminis mainly occurred on Triticum, Aegilops, and Elymus while $P$. graminis subsp. graminis var. stakmannii mainly occurred on Avena, Hordeum, and Elytrigiae. Mating between different formae speciales of $P$. graminis may occasionally occur on barberry, but signs of intervarietal sterility were shown between formae speciales (20). This agrees with Zambino and Szabo (38), who found that the sequences of the ITS (internal transcript spacer) region could be used to separate $P$. graminis $\mathrm{f}$. sp. tritici and secalis from $P$. graminis f. sp. avenae, dactylis, lolii, and poae.

Berberis spp. is not the alternate host only for $P$. graminis. A number of Puccinia species form aecia on Berberis spp. including $P$. brachypodii, $P$. pygmaea, and $P$. montanensis (7). It was recently found that $P$. striiformis, causing yellow or stripe rust on wheat also undergoes sexual reproduction on barberry (18). The presence of the alternate host potentially advances disease onset, increases the initial inoculum levels, and increases the number of races of the pathogen. The races will be more diverse in the presence of the alternate host than if the pathogen only reproduces clonally (30). Johnson (20) concluded that the hybridization of two formae speciales may broaden the range of pathogenicity, and suggested that it was accompanied by a reduction in "pathogenic intensity" on the tested hosts. Previous studies of $P$. graminis f. sp. avenae have shown that if the alternate host is present, the genetic diversity is large (4).

In Sweden most wheat and rye is planted in the fall, and $P$. graminis can survive mild winters on these crops, but stem rust in wheat is only seen on older landraces and is not a problem in modern cultivars due to effective resistance genes. The first visible signs of stem rust in rye are usually reported in the end of June or beginning of July when the crop is in the heading or soft dough stage (DC 55 to 85 [37]). For oats, which is only grown as a spring crop in Sweden, the first disease reports come approximately 2 weeks later (also DC 55 to 85), in the middle or end of July (26).

The purpose of this study was to investigate the genetic differentiation between formae speciales of $P$. graminis on two different grass hosts and to determine whether $P$. graminis collected from barberry could be matched to these formae speciales. Aecia were collected from barberry and uredinia were collected 
from oats (Avena sativa) and rye (Secale cereale). The genetic relationship was evaluated by using simple sequence repeat (SSR) markers, which previously have been used to study $P$. graminis $(4,19,33,40)$.

\section{MATERIALS AND METHODS}

Sample collection. Samples were collected from both the uredinial hosts and the aecial hosts at different locations in southern Sweden (Fig. 1). Samples from the aecial host, Berberis spp. were collected in June each year (2008 to 2010). If more than one bush was present at a site, several collections could be made. The distance between bushes in a single collection was never greater than $20 \mathrm{~m}$. At one site, when two different species of barberry were present, the samples were divided into two collections. From each collection, three to five clearly defined aecia were cut out and analyzed as separate samples.

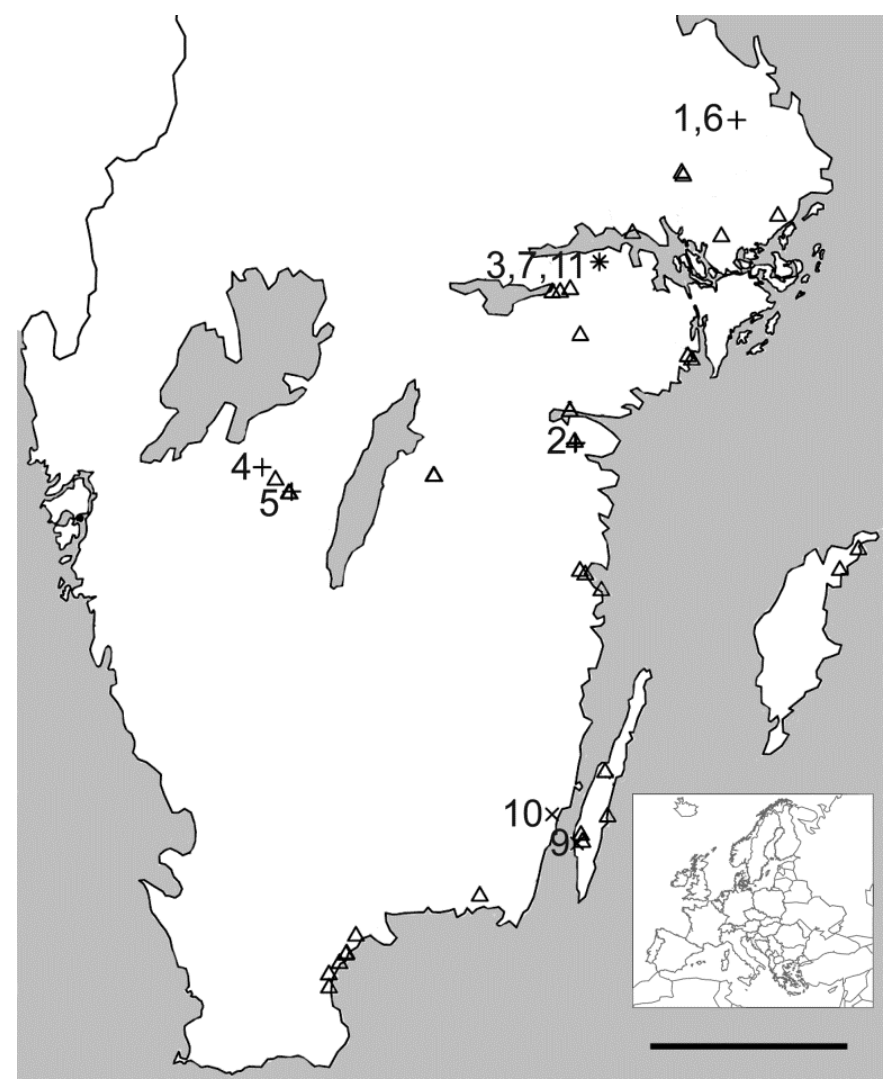

Fig. 1. Location of collection sites, oat fields $(+)$, rye fields $(\times)$, and barberry locations $(\Delta)$. Numbers correspond to the population numbers in Table 2 . Bar $=100 \mathrm{~km}$.
The collections from the grass host were done between the end of July and the end of August 2008 and 2009 (DC 83 to 92). In each field, five to eight stems were collected at 10 points, $10 \mathrm{~m}$ apart, along a straight line. In all but one field, this was repeated in three replications $10 \mathrm{~m}$ apart, creating a regular grid design of $30 \times 100 \mathrm{~m}$. In one field (Bränne Övregård) there was only one replication with 10 collections. From each collection point within a field, the stems with pustules were kept dry in a paper bag. Samples collected from oats were considered to be $P$. graminis $\mathrm{f}$. sp. avenae and those from rye $P$. graminis $\mathrm{f}$. sp. secalis. For DNA extraction, a single pustule from each collection was carefully cut out and used as a sample. When developing the method (4), a subset of single pustule isolates was made from the same source pustule and then genotyped. The genotypes from the different isolates from the same source pustules were identical or within the error margin of the allele determination procedure (data not shown). All samples from a field were treated as one population. At all field sites, the close surroundings were inspected for occurrence of Berberis spp., but no bushes were found in the field or its immediate surroundings. The collections from oats have previously been used and discussed in a study evaluating the oat stem rust population in Sweden (4).

SSR marker analysis and evaluation. The DNA extractions were carried out with OmniPrep kits (GenoTech, St. Louis) according to the manufacturer's instructions for fungal tissues with minor modifications as described by Berlin et al. (4). The samples were analyzed using 11 polymorphic SSR markers (Table 1). Amplification of the SSR markers was carried out as a multiplex reaction according to Berlin et al. (4). The samples were analyzed at the Uppsala Genome Center at Rudbeck laboratory, Uppsala University, by capillary electrophoresis analysis (ABI 3730XL DNA Analyzer). The lengths of the fragments were determined with GeneMarker (Softgenetics) to identify the different genotypes. If any sample showed more than two clear peaks at a locus, the alleles were coded as missing.

The internal transcribed spacer (ITS) region was sequenced for most of the samples collected from Berberis spp. to confirm the species identity. The rust-specific primers ITS1RustF10d and StdLSUR2a (3) were used both for polymerase chain reaction (PCR) amplification and sequencing. The same DNA samples as for the SSR marker analysis were used for the ITS region amplification. The ITS region was amplified in 50- $\mu$ l reactions, including each of the following in the final concentrations: $2 \mathrm{ng} / \mu \mathrm{l}$ DNA template, $0.02 \mathrm{mM}$ dNTP, $0.2 \mu \mathrm{M}$ of each primer, $2.75 \mathrm{mM}$ $\mathrm{MgCl}_{2}, 0.05 \mathrm{U} / \mu \mathrm{l}$ of DreamTaq DNA polymerase and DreamTaq buffer according to the manufacturer's recommendation. The PCR program included an initial denaturation at $94^{\circ} \mathrm{C}$ for $5 \mathrm{~min}$, followed by 35 cycles of denaturation at $94^{\circ} \mathrm{C}$, annealing at $57^{\circ} \mathrm{C}$ and extension at $72^{\circ} \mathrm{C}$, each for $30 \mathrm{~s}$, and finally an extension step at $72^{\circ} \mathrm{C}$ for $7 \mathrm{~min}$. The PCR products were purified with AMPure (Agencourt Bioscience Corporation, MA) according to the manu-

TABLE 1. Performance of the 11 simple sequence repeat (SSR) markers used in this study ${ }^{\mathrm{a}}$

\begin{tabular}{|c|c|c|c|c|c|c|c|c|}
\hline \multirow[b]{2}{*}{ SSR marker } & \multirow[b]{2}{*}{$\mathrm{N}_{\mathrm{a}}$} & \multirow[b]{2}{*}{$\mathrm{H}_{\mathrm{o}}$ (s.e.) } & \multirow[b]{2}{*}{$\mathrm{H}_{\mathrm{e}}$ (s.e.) } & \multirow[b]{2}{*}{$\mathrm{F}_{\mathrm{IS}}$} & \multicolumn{3}{|c|}{$\%$ missing values } & \multirow[b]{2}{*}{ Reference } \\
\hline & & & & & Barberry & Oats & Rye & \\
\hline Pgestssr021 & 8 & $0.412(0.045)$ & $0.574(0.040)$ & 0.283 & 2.1 & 2.7 & 5.8 & Berlin et al. (4) \\
\hline PgtSSR21 & 7 & $0.457(0.053)$ & $0.470(0.034)$ & 0.027 & 0.7 & 6.3 & 10.1 & Szabo (34) \\
\hline Pgestssr024 & 15 & $0.610(0.049)$ & $0.647(0.026)$ & 0.057 & 1.4 & 0.5 & 2.9 & Berlin et al. (4) \\
\hline Pgestssr109 & 10 & $0.513(0.046)$ & $0.533(0.035)$ & 0.038 & 2.1 & 5.0 & 2.9 & Zhong et al. (40) \\
\hline Pgestssr171 & 22 & $0.432(0.040)$ & $0.743(0.026)$ & 0.419 & 21.4 & 19.5 & 23.2 & Zhong et al. (40) \\
\hline Pgestssr 255 & 14 & $0.589(0.069)$ & $0.548(0.055)$ & -0.074 & 2.8 & 5.0 & 5.8 & Berlin et al. (4) \\
\hline Pgestssr 279 & 10 & $0.434(0.047)$ & $0.475(0.040)$ & 0.087 & 7.6 & 9.5 & 4.3 & Zhong et al. (40) \\
\hline Pgestssr 280 & 15 & $0.172(0.025)$ & $0.635(0.047)$ & 0.729 & 17.9 & 28.5 & 21.7 & Berlin et al. (4) \\
\hline Pgestssr 368 & 11 & $0.570(0.047)$ & $0.527(0.034)$ & -0.081 & 5.5 & 6.8 & 2.9 & Zhong et al. (40) \\
\hline PgtCAA53 & 16 & $0.253(0.104)$ & $0.297(0.091)$ & 0.149 & 1.4 & 2.7 & 14.5 & Jin et al. (19) \\
\hline PgtCAA93 & 18 & $0.385(0.097)$ & $0.582(0.088)$ & 0.337 & 9.7 & 29.4 & 8.7 & Jin et al. (19) \\
\hline
\end{tabular}

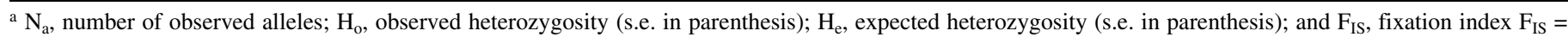
(mean $\mathrm{H}_{\mathrm{e}}-$ mean $\mathrm{H}_{\mathrm{o}}$ )/mean $\mathrm{H}_{\mathrm{e}}$. 
facturer's description and sequenced by capillary electrophoresis (3730 XL, Macrogen, South Korea). The forward and reverse ITS region sequences were aligned in SeqMan Pro (DNA Star). The species identity was controlled by comparing the acquired sequences to sequences deposited in GenBank through a BLASTN search (39) and only samples with a high similarity (at least $98 \%$ similarity and E-value of 0.0 ) were included in the study.

Genetic data analysis. Since different Puccinia species are present on barberry bushes in Sweden, the species identity of samples collected from barberry was investigated before applying the SSR markers to the samples (Supplementary Table 1). A combination of both ITS sequence identity and successful amplification of SSR markers was therefore obligatory for each aecial sample to be included in further analyses. Samples where no sequence of the ITS region was obtained were included if at least seven SSR loci gave amplification products. All samples with more than four missing values were removed from the dataset. In order to check for possible bias due to missing values, analyses were done with and without the loci with particularly high frequencies of missing values, but this did not affect the results.

To evaluate the usefulness of the primers (Table 1), the observed heterozygosity $\left(\mathrm{H}_{\mathrm{o}}\right)$ and expected heterozygosity $\left(\mathrm{H}_{\mathrm{e}}\right)$ were calculated for each SSR marker using GenAlEx6.4 (28). $\mathrm{H}_{\mathrm{o}}$ is the proportion of samples that are heterozygous at a locus, and $\mathrm{H}_{\mathrm{e}}$ is the proportion of samples expected to be heterozygous at the locus under random mating. The gene diversity is reported as the number of alleles at each locus and the gene allele frequencies were visualized in graphs.

Samples from each field site were grouped into one population, giving eight oat populations and three rye populations (Table 2). For each field population, the genotypic diversity is reported as the number of unique genotypes divided by the total number of samples within the population $(\mathrm{G} / \mathrm{N}) . \mathrm{H}_{\mathrm{o}}$ and $\mathrm{H}_{\mathrm{e}}$ within field populations were calculated using GenAlEx6.4 (28), where $\mathrm{H}_{\mathrm{o}}$ is the average observed heterozygosity and $\mathrm{H}_{\mathrm{e}}$ is the expected heterozygosity within a population at random mating. The inbreeding coefficient $\left(\mathrm{F}_{\mathrm{IS}}\right)$ was calculated using the computer program Fstat (15). To test for association among different loci, the index of association $\left(\mathrm{I}_{\mathrm{A}}\right)$ was calculated for each population separately, using the software Multilocus 1.3b (2). Due to the high percentage of missing values within particular loci, the $\mathrm{I}_{\mathrm{A}}$ test for significance was carried out with the option "missing data fixed" and replicated 1,000 times. Estimation of the selfing rate $\mathrm{s}(\mathrm{g} 2)$ from the distribution of multilocus heterozygosity in each field population was performed in the software REMS using 1,000 iterations (8). This method has been shown to be insensitive to null alleles (8).

Analyses of molecular variance (AMOVA) were carried out with Genalex6.4 with 9,999 permutations. Separate analyses were done to estimate the difference between $P$. graminis f. sp. avenae and $P$. graminis f. sp. secalis, and the difference among field populations of $P$. graminis $\mathrm{f}$. sp. avenae, and among field populations of $P$. graminis $\mathrm{f}$. sp. secalis. Clone correction was done separately for each AMOVA.

The Bayesian cluster computer program Structure (29) was used to examine the population structure within the total set of samples in order to investigate the number of genotypic clusters and to determine the ancestry of the different samples. This program assumes panmixia, i.e., that each locus is at Hardy-Weinberg equilibrium and independent of other loci, and it has proved to be robust even when these assumptions are not met. The hypothesis in our case was that the formae speciales form different populations, and the assumptions made in the analysis were mixed populations and independent alleles. The range of presumed number of genotypic clusters $(K)$ was set to 1 to 15 and the program was set to a burn-in period of 100,000 iterations followed by 100,000 iterations. The program calculates the Log likelihood for each value of $K$, and the highest likelihood value indicates the most likely number of genotypic clusters. Three independent simulations were performed to test the consistency of the result. The graphical display of the output was made in the software Distruct (31). In addition, a principal coordinate analysis (PCA) was performed with GenAlEx 6.4 to visualize the genetic pattern among all samples, based on the calculated genetic distances.

\section{RESULTS}

Eleven polymorphic SSR loci were used to genotype 290 uredinia collected from rye and oat fields, and 145 aecia collected from barberry in southern Sweden. All SSR loci were polymorphic and the number of alleles ranged between 7 and 22 for the different loci (Table 1). The $\mathrm{H}_{\mathrm{o}}$ and $\mathrm{H}_{\mathrm{e}}$ values were not statistically different from each other for seven of the 11 loci. For the remaining four loci (Pgestssr021, Pgestssr171, Pgestssr280, and PgtCAA93) $\mathrm{H}_{\mathrm{o}}$ was significantly lower than $\mathrm{H}_{\mathrm{e}}$, indicating an excess of homozygotes, which was also shown by the large $\mathrm{F}_{\text {IS }}$ values (Table 1). The allele frequencies for samples from the three hosts (barberry, oats, and rye) are presented in Figure 2. For the primers Pgestssr021, PgtSSR21, Pgestssr171, Pgestssr255, Pgestssr279, Pgestssr 280, Pgestssr368, and PgtCAA93, the allele frequencies clearly overlap among the different hosts. For three other primers, Pgtestssr024, Pgestssr109, and PgtCAA53, the allele sizes are different between samples collected from the two grass hosts, oats and rye. A bimodal distribution of alleles from barberry was present for Pgestssr024, where one peak corresponds to those from oats and the other to those from rye. A tendency for the same bimodal pattern is also seen for Pgestssr109.

TABLE 2. Population genetic data for the oats and rye field populations $\mathrm{s}^{\mathrm{a}}$

\begin{tabular}{lllllllllrrrr}
\hline Pop & Crop & \multicolumn{1}{c}{ Site } & $\begin{array}{c}\text { Day of } \\
\text { collection }^{\mathrm{b}}\end{array}$ & $\mathrm{N}$ & $\mathrm{G} / \mathrm{N}$ & $\mathrm{H}_{\mathrm{o}}$ (s.e.) & $\mathrm{H}_{\mathrm{e}}$ (s.e.) & \multicolumn{1}{c}{$\mathrm{F}_{\mathrm{IS}}$} & \multicolumn{1}{c}{$\mathrm{I}_{\mathrm{A}}$} & \multicolumn{1}{c}{$P$} & $\mathrm{~s}(\mathrm{~g} 2)$ & $P$ \\
\hline Pop1 & Oats & Ingvasta & 06.08 .08 & 28 & 1 & $0.365(0.074)$ & $0.520(0.060)$ & 0.322 & 0.398 & 0.027 & 0.017 & 0.477 \\
Pop2 & Oats & Å & 11.08 .08 & 27 & 1 & $0.388(0.060)$ & $0.504(0.044)$ & 0.251 & 0.067 & 0.333 & 0.000 & 0.678 \\
Pop3 & Oats & Bränne Övregård & 13.08 .08 & 30 & 0.9 & $0.440(0.088)$ & $0.454(0.072)$ & 0.054 & 0.065 & 0.353 & 0.032 & 0.389 \\
Pop4 & Oats & Götala & 26.08 .08 & 25 & 1 & $0.443(0.087)$ & $0.567(0.054)$ & 0.244 & -0.215 & 0.998 & 0.000 & 0.522 \\
Pop5 & Oats & Skarpenberga & 30.07 .09 & 27 & 1 & $0.414(0.066)$ & $0.560(0.060)$ & 0.281 & 0.326 & 0.063 & 0.330 & 0.001 \\
Pop6 & Oats & Ingvasta & 05.08 .09 & 25 & 1 & $0.324(0.052)$ & $0.571(0.045)$ & 0.453 & 0.101 & 0.370 & 0.000 & 0.595 \\
Pop7 & Oats & Bränne Övregård & 06.08 .09 & 29 & 1 & $0.422(0.047)$ & $0.560(0.047)$ & 0.266 & -0.096 & 0.585 & 0.000 & 0.778 \\
Pop8 & Oats & Klostergården-Dala & 07.08 .09 & 30 & 1 & $0.421(0.067)$ & $0.474(0.066)$ & 0.130 & 0.332 & 0.001 & 0.000 & 0.704 \\
Pop9 & Rye & Beteby & 22.07 .08 & 30 & 1 & $0.556(0.077)$ & $0.628(0.068)$ & 0.135 & 0.302 & 0.125 & 0.130 & 0.042 \\
Pop10 & Rye & Råby, Kölby & 29.07 .09 & 29 & 1 & $0.572(0.066)$ & $0.682(0.051)$ & 0.181 & 0.979 & 0.001 & 0.041 & 0.298 \\
Pop11 & Rye & Bränne Övregård & 05.08 .09 & 10 & 1 & $0.481(0.073)$ & $0.510(0.070)$ & 0.110 & -0.183 & 0.799 & 0.067 & 0.271 \\
\hline
\end{tabular}

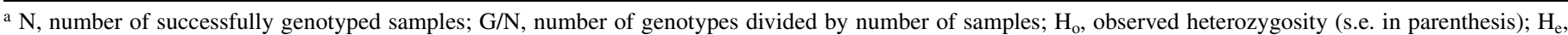
expected heterozygosity (s.e. in parenthesis); $\mathrm{F}_{\mathrm{IS}}$, fixation index $\mathrm{F}_{\mathrm{IS}}=\left(\right.$ mean $\mathrm{H}_{\mathrm{e}}-$ mean $\left.\mathrm{H}_{\mathrm{o}}\right) / \mathrm{mean}_{\mathrm{e}}$; $\mathrm{I}_{\mathrm{A}}$, index of association and its $P$ value with the option missing value fixed; and $\mathrm{s}(\mathrm{g} 2)$, estimated rate of selfing and its $P$ value $\left(\mathrm{H}_{0}: \mathrm{g} 2=\mathrm{s}=0\right)$.

b Day.month.year. 
All but one population had a $\mathrm{G} / \mathrm{N}$ ratio of 1 (Table 2 ), indicating high genotypic diversity and thus little clonality within each field population. The $\mathrm{H}_{\mathrm{o}}$ spans between 0.324 and 0.572 and the $\mathrm{H}_{\mathrm{e}}$ spans between 0.454 and 0.682 . The inbreeding coefficient $\left(\mathrm{F}_{\mathrm{IS}}\right)$ ranged between 0.054 and 0.453 . In one population, collected from an oat field (Bränne Övregård), the $\mathrm{F}_{\mathrm{IS}}$ was close to zero which indicates random mating (Table 2). The estimation of selfing rates $\mathrm{s}(\mathrm{g} 2)$ was significant for two field populations, one collected from oats (Skarpenberga) and one collected from rye (Beteby). This indicates a substructure within those two locations. The $I_{A}$ ranged between -0.215 and 0.979 (Table 2). For eight of the 11 studied field populations the $I_{A}$ was not significantly different from zero. Thus there is no evidence that these populations were not in linkage equilibrium.
Three AMOVAs were used to examine the variation between the two formae speciales, and the variation among populations within the two formae speciales separately (Table 3). The first AMOVA showed that the difference between formae speciales was $34 \%(P<0.001)$, and the variation within formae speciales was $66 \%$. The variation among field populations within $P$. graminis f. sp. avenae was $10 \%(P<0.001)$. Within $P$. graminis f. sp. secalis, the variation among field populations was $12 \%$ $(P<0.001)$. This means that there was a clear differentiation between the two formae speciales. A large proportion of the variation was also present within the field populations of each forma specialis.

By using the program Structure, the number of inferred clusters $(K)$ that had the highest Log likelihood was six (Fig. 3). Samples
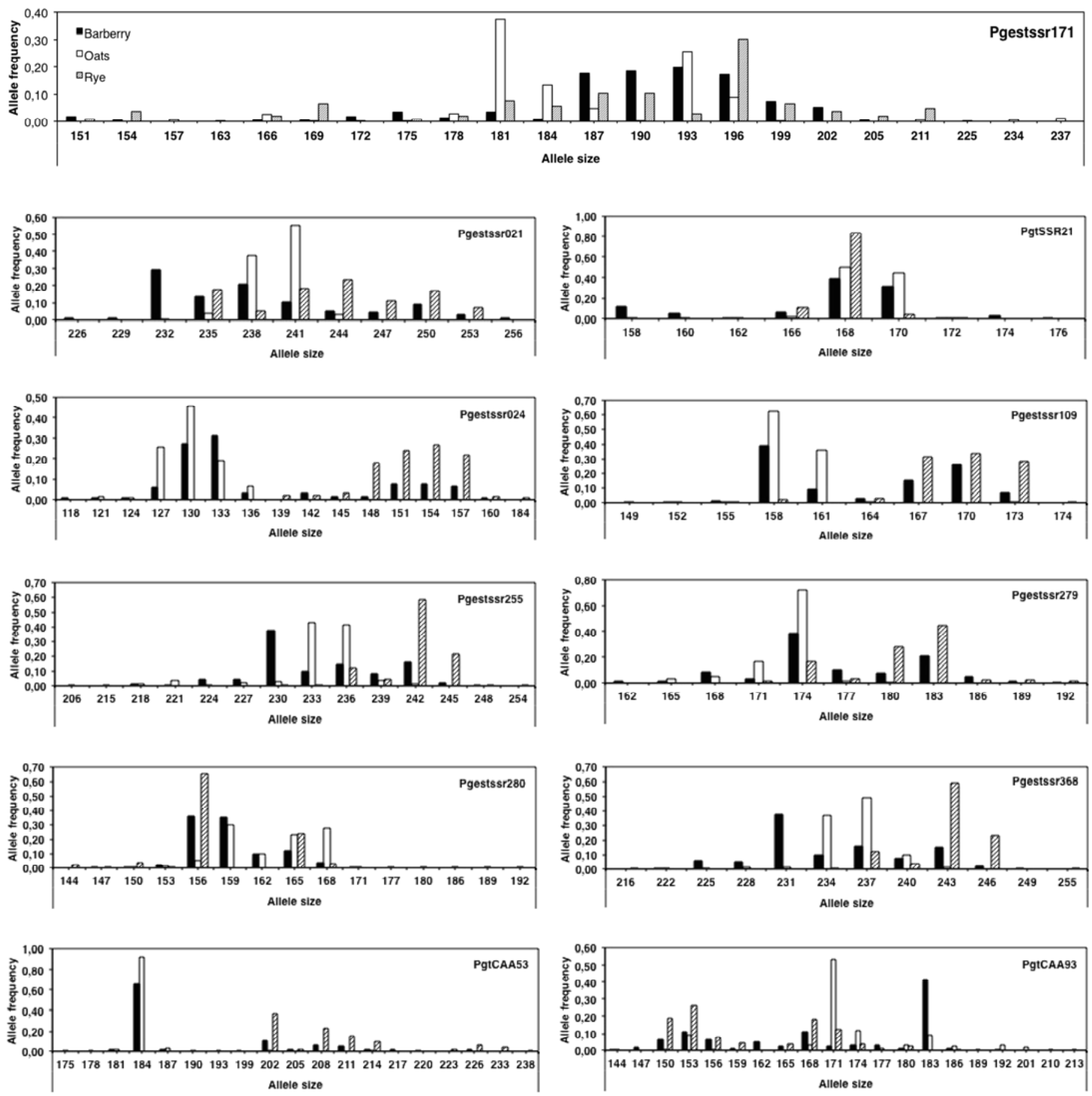

Fig. 2. Allele frequencies of 11 simple sequence repeat markers used for genotyping Puccinia graminis collected from barberry (black bars), oats (white bars), and rye (striped bars). 
from oats showed ancestry primarily from two of these inferred clusters (yellow and purple) either singly or in combination (Fig. 3 ). Those from rye showed ancestry primarily from a third cluster (light blue). Samples collected from barberry showed ancestry from all six inferred clusters. Some of the barberry samples shared ancestry with the samples from oats or rye, whereas other barberry samples did not (red, green, gray).

The PCA showed that the samples collected from oats and rye were different and that the samples collected from barberry formed a larger group in which samples from both formae speciales were represented (Fig. 4). The first axis of the PCA explained $41 \%$ and the second explained $19 \%$ of the differences between the individual samples.

\section{DISCUSSION}

$P$ graminis collected from the studied grass hosts, oats and rye, could be divided into two genetically separate groups, as indicated by the AMOVA analysis. This is also supported by the Structure analysis (Fig. 3) and the PCA (Fig. 4), where it is shown that these formae speciales are genetically different, and that they are genetically similar to some of the $P$. graminis samples found on the barberry bushes. The genetic differentiation was further proved by non-overlapping allele distributions for the two formae speciales at three SSR loci.

An alternate explanation of this differentiation is that it is due to geographical differences. The collections from Bränne Övregård (populations 7 and 11, from oats and rye, respectively) however, were collected in adjacent fields and show clear differentiation. Eriksson and Henning (10) described the phenotypic differences between samples of $P$. graminis infecting different grass hosts, both by inoculation and morphological studies. Our study confirms their results in that genetic differences were found between the two studied formae speciales.
In addition to $P$. graminis $\mathrm{f}$. sp. avenae and $P$. graminis $\mathrm{f}$. sp. secalis three additional groups, and possibly hybrids between the different groups, were found on barberry (Fig. 3). P. graminis can infect several hundred species (24) and the barberry samples (other than the ones that could be derived as $P$. graminis $\mathrm{f}$. $\mathrm{sp}$. avenae or $P$. graminis $\mathrm{f}$. sp. secalis) may belong to any of the other formae speciales infecting wild grasses present in Sweden. Different formae speciales of $P$. graminis exist in parallel and seem to rarely exchange genetic material on barberry. Earlier studies $(20,21)$ have shown that the fitness of hybrids is lower than for pure formae speciales. Hybrids will occur only in low frequencies, if present at all, since their ability to compete with pure formae speciales is poor. In this study, one sample collected from a rye field appears to be a hybrid between $P$. graminis $\mathrm{f}$. sp. secalis and $P$. graminis f. sp. avenae (Fig. 3). The allelic composition of the sample supported this conclusion since it had one allele characteristic of each forma specialis at four loci (alleles 165 and 172 for Pgestssr21, 171 and 180 for Pgestssr279, 233 and 242 for Pgestssr255, and 234 and 237 for Pgestssr368; Fig. 2). As demonstrated by Johnson (20), hybridization is possible but it probably occurs rarely and the lack of fitness of the progeny will reduce their importance. The reproductive barrier appears to be in fertilization of the receptive hyphae by pycniospores since artificial crossings between $P$. graminis $\mathrm{f}$. sp. trititci/secalis and $P$. graminis f. sp. avenae rarely are successful (20).

Samples genetically similar to one or the other of the two formae speciales were found on barberry. This, together with the high genetic diversity within both formae speciales studied, and no or low significance of the Index of Association is consistent with sexual reproduction, which also has been shown in a previous study (4). The presence of the alternate host and the possibility for sexual recombination will enable the fungus to become extremely diverse in Sweden compared with populations developing in the absence of barberry, where clonal reproduction

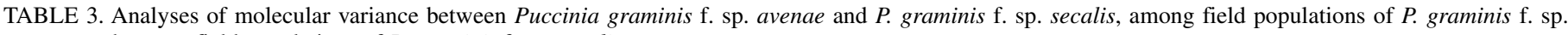
avenae, and among field populations of $P$. graminis f. sp. secalis ${ }^{\mathrm{a}}$

\begin{tabular}{|c|c|c|c|c|c|c|}
\hline Source & df & Sum of squares & Mean of squares & Estimated variance & $\%$ & $P$ value \\
\hline Between formae speciales & 1 & 536.1 & 536.1 & 5.04 & $34 \%$ & $<0.001$ \\
\hline Within formae speciales & 282 & $2,751.7$ & 9.8 & 9.76 & $66 \%$ & \\
\hline Total & 283 & $3,287.8$ & & 14.80 & $100 \%$ & \\
\hline Among field populations of $P$. graminis f. sp. avenae & 7 & 241.0 & 34.43 & 0.95 & $10 \%$ & $<0.001$ \\
\hline Within field populations of $P$. graminis f. sp. avenae & 210 & $1,827.3$ & 8.70 & 8.70 & $90 \%$ & \\
\hline Total & 217 & $2,068.3$ & & 9.65 & $100 \%$ & \\
\hline Among field populations of $P$. graminis f. sp. secalis & 2 & 73.3 & 36.66 & 1.28 & $12 \%$ & $<0.001$ \\
\hline Within field populations of $P$. graminis f. sp. secalis & 66 & 632.5 & 9.58 & 9.58 & $88 \%$ & \\
\hline Total & 68 & 705.8 & & 10.86 & $100 \%$ & \\
\hline
\end{tabular}

a Clone correction was done separately for each analyzed population.

\section{Barberry}

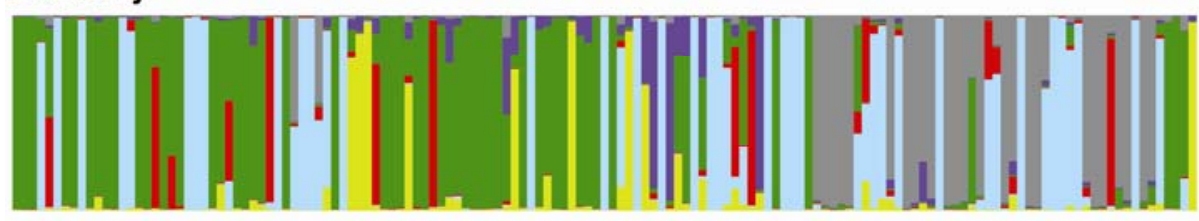

\section{Rye}

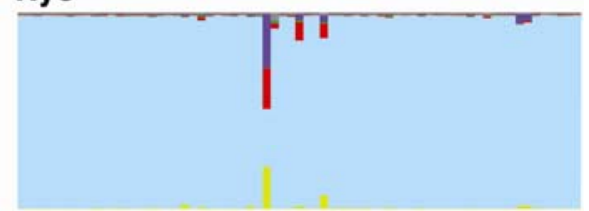

\section{Oats}

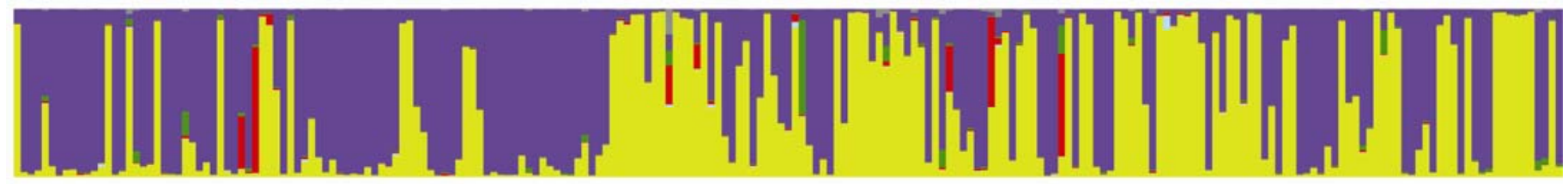

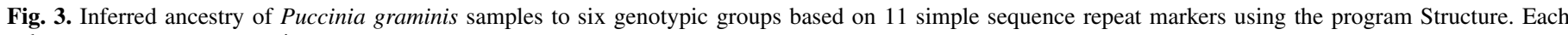
color represents one genotypic group. 
dominates, such as those in Australia (23). Currently the race diversities of $P$. graminis $\mathrm{f}$. sp. avenae and $P$. graminis $\mathrm{f}$. $\mathrm{sp}$. secalis in Sweden are not known, but we can only speculate that the large number of genotypes could lead to a large number of races (25).

Limited inbreeding has produced local populations and this can be seen since the $F_{\text {IS }}$ value is larger than zero for most field populations. The analyses for two of the field populations (Skarpenberga and Beteby) also indicate significance for what is referred to as the rate of selfing $(\mathrm{s}(\mathrm{g} 2))$, which in this case indicates inbreeding. For both of these fields, barberry bushes were found at a distance of 0.5 to $2.0 \mathrm{~km}$ from the field (Fig. 1), and such a situation may facilitate development of localized populations.

The importance of barberry as an alternate host may differ between the formae speciales. The host shift in $P$. graminis does not only enable genetic recombination but also enables the rust to infect annual crops, which are present during a relatively short growing season. A small amount of clonal survival may be one possible explanation why $P$. graminis $\mathrm{f}$. sp. secalis is genetically more homogenous than P. graminis f. sp. avenae in Sweden (Fig. 3 ), since rye is a fall-sown crop where uredinia may overwinter. Oats is only sown in the spring in Sweden, and P. graminis f. sp. avenae cannot overwinter clonally on this host. Therefore a host shift to barberry, including obligate genetic recombination each year is the only way of survival. This hypothesis is supported by the observations that the first signs of disease are reported from rye approximately 2 to 3 weeks before the disease is found in oats. This also comports with both Eriksson's (10) and Hermansen's (16) findings that $P$. graminis f. sp. tritici and $P$. graminis $\mathrm{f}$. $\mathrm{sp}$. secalis were reported earlier in the field than $P$. graminis $\mathrm{f}$. sp. avenae where pustules appeared approximately 2 weeks later. The genotypes infecting earlier will dominate the population at the end of the season $(27,36)$.

Analyses did not uncover any signs of recent bottlenecks for field populations of either $P$. graminis f. sp. avenae or $P$. graminis f. sp. secalis (calculations of $M$ value (12), data not shown), though one may surmise that the populations experience them yearly or that there was one large bottleneck during the barberry eradication period.

The percentages of missing values of the SSR markers were high for some loci (Table 1). Pgestssr171 and Pgestssr280 have many missing values for all hosts, while PgtCAA53 and PgtCAA93 had many missing values for rye and oats respectively. One possible explanation is that null alleles are present. Species with large effective population sizes, like $P$. graminis in this case (data not shown), may be expected to have high null allele frequencies since the genetic variation within the species increases with the population size and mutations in the flanking regions and primer sites may be present (6). The primers used in this study were originally designed for $P$. graminis f. sp. tritici, and this may also have affected the null allele frequencies.

The many methods used to classify the divisions in $P$. graminis, of which formae speciales, subspecies, and varieties represent some of these attempts, indicate that it is not a simple species. We show that the genetic diversity is high within each forma specialis and that $P$. graminis f. sp. avenae and $P$. graminis $\mathrm{f}$. $\mathrm{sp}$. secalis are clearly different in Sweden. Abbasi (1) studied the sequences of the ITS region and found that the species is highly complex, and that neither morphological nor the genetic characters provide a full answer to the evolutionary relationship between samples from different parts of the world. The reproductive barrier reported here for $P$. graminis clearly separates $P$. graminis $\mathrm{f}$. sp. secalis and $P$. graminis $\mathrm{f}$. sp. avenae despite the fact that they meet on barberry. But, it may be premature to assume that this phenomenon applies on a worldwide basis.

\section{ACKNOWLEDGMENTS}

We thank the Swedish Farmers Foundation for Agricultural Research (SLF) and the Swedish University of Agricultural Sciences (SLU) for funding this research and Plant protection specialists at the Swedish Board of Agriculture for regular updates on the rust situation.

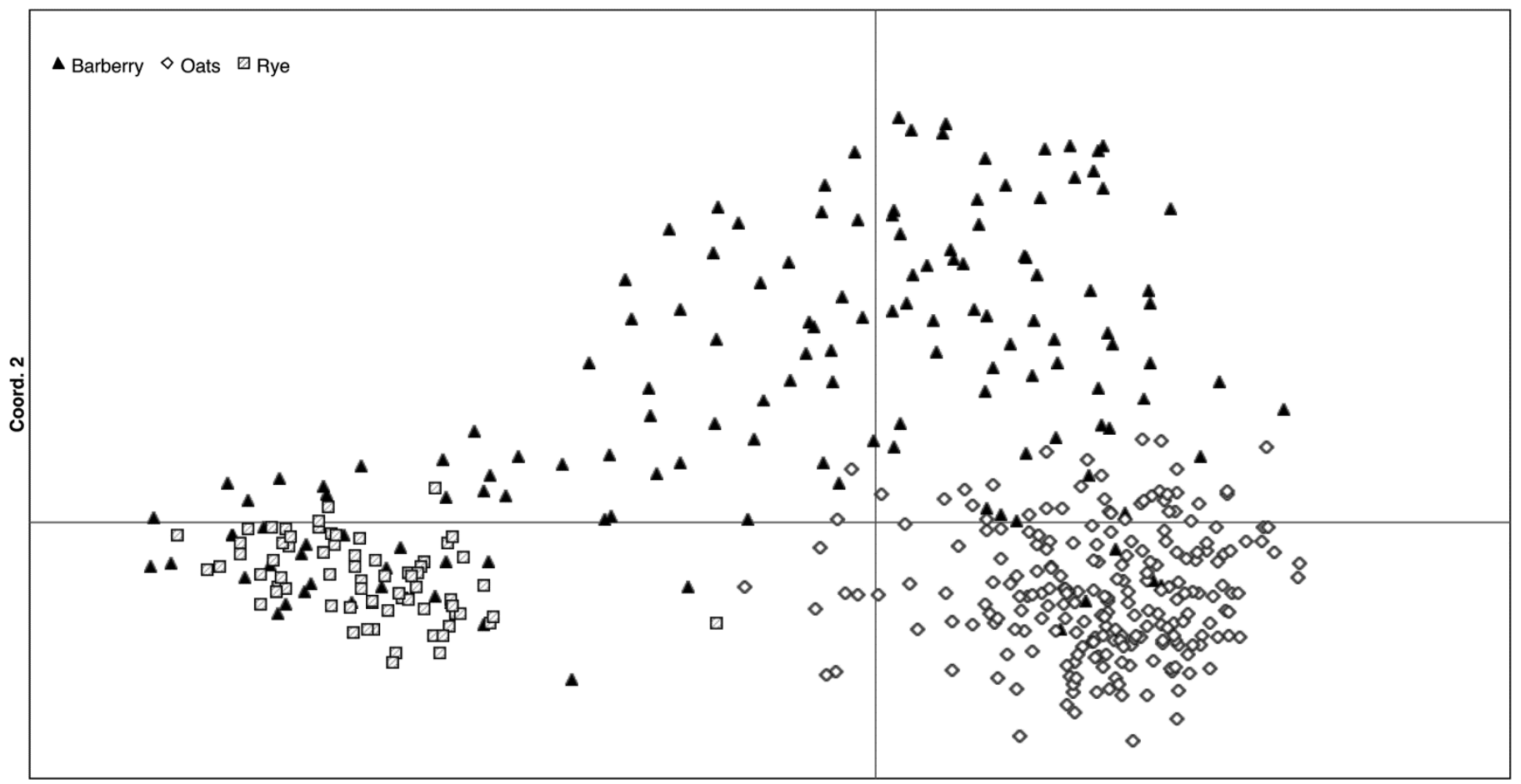

Coord. 1

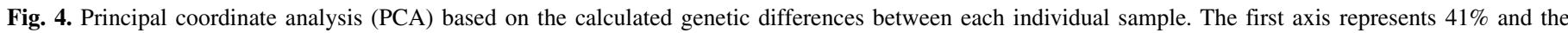
second represents $19 \%$ of the total genetic differences between the individual samples. 


\section{LITERATURE CITED}

1. Abbasi, M., Goodwin, S. B., and Scholler, M. 2005. Taxonomy, phylogeny, and distribution of Puccinia graminis, the black stem rust: New insights based on rDNA sequence data. Mycoscience 46:241-247.

2. Agapow, P.-M., and Burt, A. 2001. Indices of multilocus linkage disequilibrium. Mol. Ecol. Notes. 1:101-102.

3. Barnes, C. W., and Szabo, L. J. 2007. Detection and identification of four common rust pathogens of cereals and grasses using real-time polymerase chain reaction. Phytopathology 97:717-727.

4. Berlin, A., Samils, B., Djurle, A., Wirsén, H., Szabo, L., and Yuen, J. 2012. Disease development and genotypic diversity of Puccinia graminis f. sp. avenae in Swedish oat fields. Plant. Pathol. (In press.)

5. Bertilsson, A., Aronsson, L.-E., Bohlin, A., Börjeson, G., Geijer, M., Ivarsson, R., Janson, O., and Sahlin, E. 2002. Västergötlands flora. SBTförlag, Lund, Sweden.

6. Chapuis, M.-P., and Estoup, A. 2007. Microsatellite null alleles and estimation of population differentiation. Mol. Biol. Evol. 24:621-631.

7. Cummins, G. B., and Greene, H. C. 1966. A review of the grass rust fungi that have uredial paraphyses and aecia on Berberis-Mahonia. Mycologia 58:702-721.

8. David, P., Pujol, B., Viard, F., Castella, V., and Goudet, J. 2007. Reliable selfing rate estimates from imperfect population genetic data. Mol. Ecol. 16:2474-2487.

9. Edqvist, M., and Karlsson, T. 2007. Smålands flora. SBF-förlaget, Uppsala, Sweden.

10. Eriksson, J., and Henning, E. 1896. Die Getrideroste ihre Geschichte und Natur sowie Massregeln gegen dieselben. Meddelande från KongLantbruks-Akademins Experimentalfält. Vol. 38. P. A. Nordstedt \& Söner, Stockholm, Sweden.

11. Fröberg, L. 2006. Blekinges flora, SBF-förlaget, Uppsala, Sweden.

12. Garza, J. C., and Williamson, E. G. 2001. Detection of reduction in population size using data from microsatellite loci. Mol. Ecol. 10:305318.

13. Gäumann, E. 1959. Die Rostpilze Mitteleuropas. Biträge zur Kryptogamenflora der Schweiz. Vol. Band XII. Buchdruckeri Büchler \& Co., Bern, Switzerland.

14. Georgson, K. 1997. Hallands flora. SBF-förlaget, Lund, Sweden.

15. Goudet, J. 1995. Fstat version 1.2: A computer program to calculate Fstatistics. J. Hered. 86:485-486.

16. Hermansen, J.E. 1968. Studies on the spread and survival of cereal rust and midlew diseases in Denmark. Doctoral thesis. Department of Plant Pathology, The Royal Veterinary and Agricultural College, Copenhagen, Denmark.

17. Jin, Y. 2011. Role of Berberis spp. as alternate hosts in generating new races of Puccinia graminis and P. striiformis. Euphytica 179:105-108.

18. Jin, Y., Szabo, L. J., and Carson, M. 2010. Century-old mystery of Puccinia striiformis life history solved with the identification of Berberis as an alternate host. Phytopathology 100:432-435.

19. Jin, Y., Szabo, L. J., Rouse, M. N., Fetch, T., Jr., Pretorius, Z. A., Wanyera, R., and Njau, P. 2009. Detection of virulence to resistance gene Sr36 within the TTKS race lineage of Puccinia graminis f. sp. tritici. Plant Dis. 93:367-370.
20. Johnson, T. 1949. Intervarietal crosses in Puccinia graminis. Can. J. Res., Sect. C. 27:45-65.

21. Johnson, T., and Newton, M. 1933. Hybridization between Puccinia graminis tritici and Puccinia graminis avenae. In: Proceedings of the World's Grain Exhibition and Conference, Canada.

22. Jonsell, L. 2010, Upplands flora. SBF-förlaget, Uppsala, Sweden.

23. Keiper, F. J., Haque, M. S., Hayden, M. J., and Park, R. F. 2006. Genetic diversity in Australian populations of Puccinina graminis f. sp. aveane. Phytopathology 96:96-104.

24. Leonard, K. J., and Szabo, L. J. 2005. Stem rust of small grains and grasses caused by Puccinia graminis. Mol. Plant. Pathol. 6:99-111.

25. Loegering, W. Q., and Powers, H. R., Jr. 1962. Inheritance of pathogenicity in a cross of physiological races 111 and 36 of Puccinia graminis f. sp. tritici. Phytopathology 52:547-554.

26. Mellqvist, E., and Waern, P. 2010. Svampbekämpning i havre. In: Försöksrapport 2009 för Mellansvenska försökssamarbetet och Svensk raps, Hushållningssällskapens Multimedia, Sweden.

27. O'Hara, R. B., and Brown, J. K. M. 1996. Immigration of the barley powdery mildew pathogen into field plots of barley. Plant Pathol. 45:1071-1076.

28. Peakall, R., and Smouse, P. E. 2006. GENALEX 6: Genetic analysis in Excel. Population genetic software for teaching and research. Mol. Ecol. Notes 6:288-295.

29. Pritchard, J. K., Stepehns, M., and Donelly, P. 2000. Inference of population structure using multilocus genotype data. Genetics 155:945959.

30. Roelfs, A. P. 1982. Effects of barberry eradication on stem rust in the United States. Plant Dis. 66:177-181.

31. Rosenberg, N. A. 2004. DISTRUCT: A program for the graphical display of population structure. Mol. Ecol. Notes 4:137-138.

32. Rydberg, H., and Wanntorp, H.-E. 2001. Sörmlands flora, Botaniska sällsk. i Stockholm, Stockholm, Sweden.

33. Szabo, L. J. 2007. Development of simple sequence repeat markers for the plant pathogenic rust fungus, Puccinia graminis. Mol. Ecol. Notes 7:92-94.

34. Tyler, T. 2007. Floran i Skåne. Arterna och dess utbredning. Lunds Botaniska Förening, Lund, Sweden.

35. Urban, Z. 1967. The taxonomy of some European graminicolous rusts. Česka Mykologie 21:12-16.

36. Yuen, J. E. 2012. Modelling pathogen competition and displacementPhytophthora infestans in Scandinavia. Eur. J. Plant. Pathol. Online publication. DOI: 10.1007/s10658-011-9933-9

37. Zadoks, J. C., Chang, T. T., and Konzak, C. F. 1974. A decimal code for the growth stages of cereals. Weed Res. 14:415-421.

38. Zambino, P. J., and Szabo, L. J. 1993. Phylogenetic relationships of selected cereal and grass rusts based on rDNA sequence analysis. Mycologia 85:401-414.

39. Zhang, Z. S. S., Wagner, L., and Miller, W. 2000. A greedy algorithm for aligning DNA sequences. J. Comput. Biol. 7:203-214.

40. Zhong, S., Leng, Y., Friesen, T. L., Faris, J. D., and Szabo, L. J. 2009. Development and characterization of expressed sequence tag-derived microsatellite markers for the wheat stem rust fungus Puccinia graminis $\mathrm{f}$. sp. tritici. Phytopathology 99:282-289. 